\title{
Modelling and optimization of submerged friction stir welding parameters for AA6061-T6 alloy using RSM
}

\author{
C. Rathinasuriyan, V. S. Senthil Kumar* \\ Department of Mechanical Engineering, CEGC, Anna University, Chennai 600025, Tamil Nadu, India
}

Received 10 November 2014, received in revised form 12 January 2015, accepted 3 February 2015

\begin{abstract}
This paper demonstrates submerged friction stir welding (SFSW) of the AA6061-T6 alloy at optimized water head for achieving higher tensile strength. The experiments were conducted based on three factors, three levels, and the Box-Benham design with the full replication technique, which is used to minimize the number of experiments. The three factors considered are the tool rotational speed (rpm), welding speed $\left(\mathrm{mm} \mathrm{min}^{-1}\right)$ and water head $(\mathrm{mm})$. The effect of these factors on the weld of AA6061-T6 was analysed, using response surface methodology (RSM), and a mathematical model was also developed to optimize the submerged friction stir welding process parameters to attain the maximum tensile strength of the joint. The experimental results confirmed the effectiveness of the method. Finally, the temperature distribution and grain size were investigated under the optimized conditions.
\end{abstract}

K e y w or d s: friction stir welding (FSW), submerged friction stir welding (SFSW), response surface methodology (RSM)

\section{Introduction}

Friction stir welding (FSW) is a very effective solid state joining process. This joining technique is energy efficient, environment-friendly, and versatile. It can be used to join high strength aerospace aluminium alloys and other metallic alloys that are hard to weld by conventional fusion welding. In FSW, a non-consumable rotating tool with a special geometry, consisting of a pin and a shoulder, enters the weld seam and joins the workpieces, by traversing along the seam. In recent years, particular interest has been taken to improve the joint properties by controlling the temperature level. To do so, water is sprayed onto the welding tool and the top surface of the weld sample during friction stir welding [1, 2]. Fratini et al. [3] found that the joint properties improved to some extent in the joints that followed the water spraying procedure compared to the normal joints. Douglas et al. [4] used submerged friction stir processing for creating ultrafinegrained bulk materials through severe plastic deformation. The present authors [5-10] conducted underwater FSW of aluminium alloy and found that the tensile strength of the underwater joint was higher than that for water spraying method of a normal joint. Zhang et al. [5] found the maximum tensile strength of $360 \mathrm{MPa}$ during underwater welding of the 2219-T6 aluminium alloy. This value is $6 \%$ higher than that of the normal FSW. Fu et al. [11], during their submerged welding of 7050 high strength aluminium alloy in hot water, determined the ratio of the ultimate tensile strength and elongation of the joint welded to the base metal. They found the ratio of the ultimate tensile strength and elongation of the joint welded to the base metal to be 92 and $150 \%$, respectively. Liu et al. [8] achieved a tensile strength of $324 \mathrm{MPa}$ and $421 \mathrm{MPa}$, respectively, in normal and underwater welds. It is equivalent to 75 and $79 \%$ of the base metal of 2219 aluminium alloy. They also found SFSP helpful in achieving better mechanical properties compared to those of normal FSP. Zhang et al. [9] have found underwater joints of the 2219-T6 aluminium alloy to attain the maximum tensile strength compared to that of normal joints. They further confirmed the positive effect of water cooling on strength improvement for the FSW of heat treatable aluminium alloy. Liu et al. [10] in their work found an intrinsic reason for the maximum of tensile strength in underwater welding compared to the nor-

*Corresponding author: tel.: 0091 9444952438; e-mail address: vssk70@gmail.com 
Table 1. Chemical composition of AA 6061-T6 (wt.\%)

\begin{tabular}{cccccccccc}
\hline $\mathrm{Al}$ & $\mathrm{Cr}$ & $\mathrm{Cu}$ & $\mathrm{Fe}$ & $\mathrm{Mg}$ & $\mathrm{Mn}$ & $\mathrm{Si}$ & $\mathrm{Ti}$ & $\mathrm{Zn}$ & 0.010 \\
\hline 98.265 & 0.120 & 0.280 & 0.310 & 0.430 & 0.061 & 0.516 & 0.008 & 0 \\
\hline
\end{tabular}

Ta ble 2. Welding parameters used to perform the SFSW process

\begin{tabular}{clcccc}
\hline S. No. & Parameter & Symbol & Low & Medium & High \\
\hline 1. & Rotational speed $(\mathrm{rpm})$ & $\omega$ & 800 & 1000 & 1200 \\
2. & Welding speed (mm min & -1 & & 60 \\
3. & Water head (mm) & $v$ & 30 & 45 & 30 \\
\hline
\end{tabular}

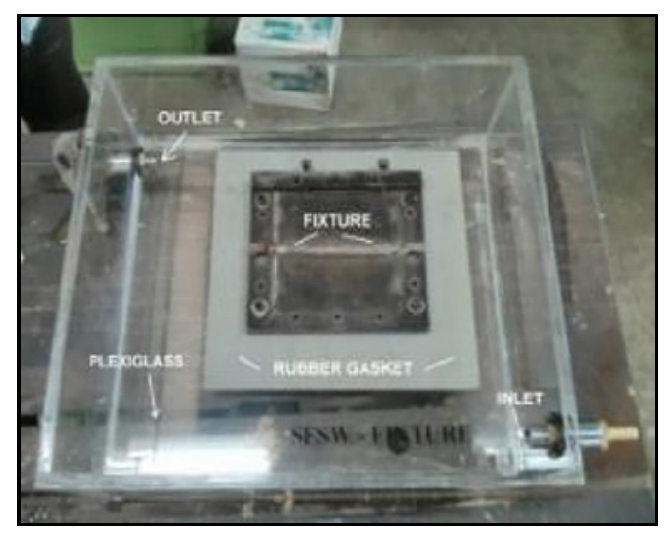

Fig. 1. Fabrication tank and fixture setup for SFSW.

mal welding of the 2219-T6 aluminium alloy. Darras et al. [12] obtained $18.3 \%$ elongation in submerged hot water condition, but only $16.7 \%$ elongation obtained in the normal condition in AZ31B-O Magnesium alloy submerged welding.

From the literature, it has been noted that none of the previous research works considered water head (the water level from the surface of the weld sample) as a parameter in submerged friction stir welding. In this study, AA6061-T6 alloy has been subjected to SFSW at various water heads from the surface of the weld sample. The effects of the water head (mm) which affects the process of submerged friction stir welding while joining 6061-T6 aluminium alloy have been studied. A mathematical model has been developed to predict the tensile strength of the weld joints. Using this model, the optimization of the welding parameter combinations for maximizing the tensile strength variation was identified. However, this work has not been carried before.

\section{Experimental set-up}

In this research, an AA6061-T6 aluminium al-

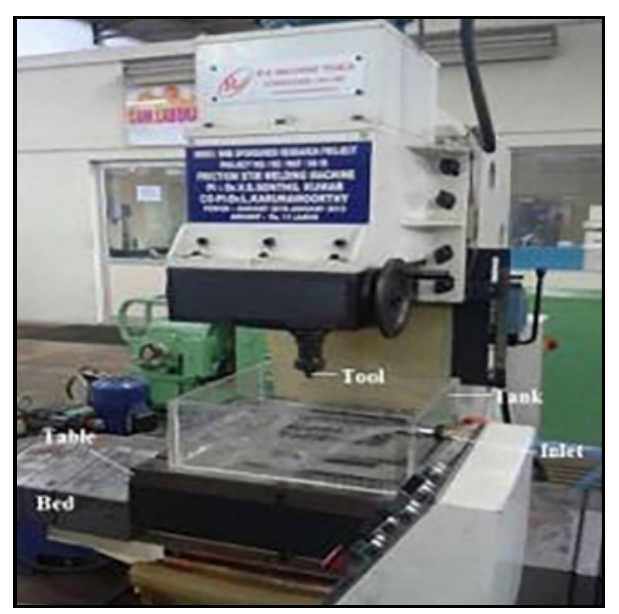

Fig. 2. Submerged friction stir welding experimental setup.

loy plate was selected with dimensions of $120 \times 140 \times 6 \mathrm{~mm}^{3}$. The chemical composition of the AA6061-T6 aluminium alloy is presented in Table 1 . Mild Steel $(0.3 \%$ $\mathrm{C}$ ) is widely used for the fixture, because of its ability to withstand higher rate of wear. AKRYLIK (PlexiGlass) has been selected as the material of the tank, keeping in mind the purpose of the vicinity of friction stir welding, and also to measure directly the level of the water used in the tank. Various tensile strengths have been obtained while changing the water heads. A rectangular tank of dimensions $450 \times 400 \times 160 \mathrm{~mm}^{3}$ was used, and mounted upon the table to which a rubber gasket was attached in between the fixture and the tank, to make it waterproof, as shown in Fig. 1. The fixture was fixed inside the tank by bolting it to the table, and the various samples were clamped on it. Water was poured at room temperature into the tank so that the top surface of the samples was immersed in it. The water head was chosen by taking into account the thickness of the gasket sheet, and the thickness of the fixture $(\sim 30 \mathrm{~mm})$. The water head was gradually increased by $10 \mathrm{~mm}$ of the head for each trial. The submerged friction stir welding experimental setup is 
Table 3. Design matrix and experimental results

\begin{tabular}{|c|c|c|c|c|c|c|c|}
\hline \multirow{2}{*}{ S. No. } & \multicolumn{3}{|c|}{ Code units } & \multicolumn{3}{|c|}{ Actual value } & \multirow{2}{*}{$\frac{\text { Tensile strength }(\mathrm{MPa})}{\text { Observed }}$} \\
\hline & $\omega$ & $\nu$ & $h$ & $\omega$ & $\nu$ & $h$ & \\
\hline 1 & 0 & 0 & 0 & 1000 & 45 & 20 & 172 \\
\hline 2 & -1 & 0 & +1 & 800 & 45 & 30 & 162 \\
\hline 3 & +1 & 0 & -1 & 1200 & 45 & 10 & 198 \\
\hline 4 & 0 & -1 & -1 & 1000 & 30 & 10 & 187 \\
\hline 5 & -1 & -1 & 0 & 800 & 30 & 20 & 181 \\
\hline 6 & +1 & -1 & 0 & 1200 & 30 & 20 & 210 \\
\hline 7 & 0 & 0 & 0 & 1000 & 45 & 20 & 174 \\
\hline 8 & -1 & 0 & -1 & 800 & 45 & 10 & 168 \\
\hline 9 & +1 & 0 & +1 & 1200 & 45 & 30 & 193 \\
\hline 10 & -1 & +1 & 0 & 800 & 60 & 20 & 161 \\
\hline 11 & 0 & 0 & 0 & 1000 & 45 & 20 & 174 \\
\hline 12 & 0 & +1 & -1 & 1000 & 60 & 10 & 169 \\
\hline 13 & +1 & +1 & 0 & 1200 & 60 & 20 & 185 \\
\hline 14 & 0 & -1 & +1 & 1000 & 30 & 30 & 181 \\
\hline 15 & 0 & +1 & +1 & 1000 & 60 & 30 & 164 \\
\hline
\end{tabular}

shown in Fig. 2. The volume of the water in relation to the water head for the low level amounts to $2.7 \mathrm{l}$. Similarly, it is increased at various levels as shown in Table 2. The SFSW tool was made from H13 steel [13]. The maximum shoulder diameter, pin diameter and pin length of the tool have been taken 15,6 , and $5 \mathrm{~mm}$, respectively, as shown in Fig. 3. The experiments have been conducted based on three factors, three levels, and the Box-Benham design, with the full replication technique. It consists of 15 sets of coded conditions [5] as shown in Table 3 . The actual welded specimen used for joining aluminium is shown in Fig. 4. The specimens were cut, according to the ASTM [2448] international codes for testing the strength of the joint, by using the Electric Discharge Machine (EDM), as shown in Fig. 5. A universal testing machine has been used to determine the tensile strength which is the longitudinal direction of the welded sample, and some of the tested samples are shown in Fig. 6. The K-type thermocouple was fixed to the plate to measure the temperatures at various junctions. The measured locations were marked at the heat-affected zone ( $8 \mathrm{~mm}$ from the weld centre) and then extended up to $14 \mathrm{~mm}$ on the advancing side. Space was $3 \mathrm{~mm}$ between the adjacent measured locations [7]. The thermocouple 4 was used to measure the water temperature in submerged condition. The exact locations of the thermal couples are shown in Fig. 7. Microstructure characterization was analysed on the cross sections of the welded plates, using Optical Microscopy (OM). The polished samples were etched with Keller's reagent [14] (a mixture of $2.5 \mathrm{ml}$ nitric acid, $1.5 \mathrm{ml}$ hydrochloric acid, $1 \mathrm{ml}$ hydrofluoric acid, and $95 \mathrm{ml}$ water).

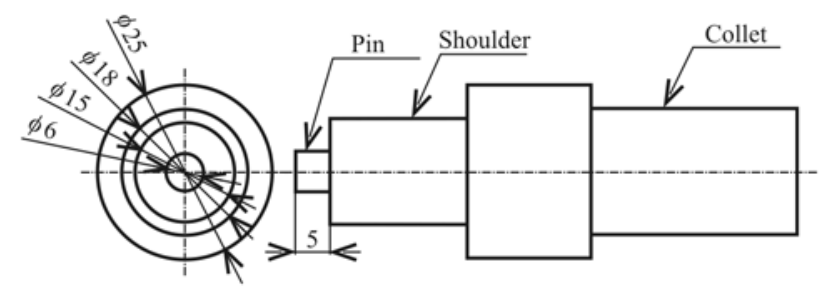

Fig. 3. Schematic view of underwater FSW tool, (unit: $\mathrm{mm})$.

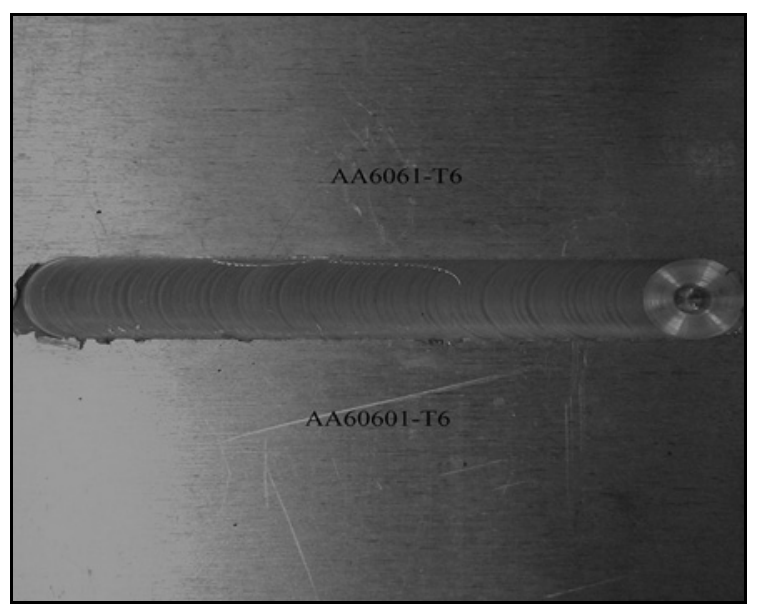

Fig. 4. Welded specimen.

\section{Results and discussion}

\subsection{Mathematical model development}

Response Surface Methodology (RSM) is a collection of mathematical and statistical techniques that 
Table 4. Analysis of variance for strength

\begin{tabular}{lcccccc}
\hline Source & DF & Sum of squares & Mean square & $F$ & $P$ & Remark \\
\hline Model & 9 & 2758.43 & 306.493 & 66.15 & 0.0001 & significant \\
$A$ & 1 & 1624.50 & 94.737 & 20.45 & 0.006 & significant \\
significant \\
$B$ & 1 & 800.00 & 36.026 & 7.78 & 0.039 & insignificant \\
$C$ & 1 & 60.50 & 8.203 & 1.77 & 0.241 & significant \\
$A^{2}$ & 1 & 228.39 & 233.853 & 50.47 & 0.001 & significant \\
$B^{2}$ & 1 & 34.29 & 32.314 & 6.97 & 0.046 & insignificant \\
$C^{2}$ & 1 & 4.01 & 4.006 & 0.86 & 0.395 & insignificant \\
$A * B$ & 1 & 6.25 & 6.250 & 1.35 & 0.298 & insignificant \\
$A * C$ & 1 & 0.25 & 0.250 & 0.05 & 0.826 & insignificant \\
$B * C$ & 1 & 0.25 & 0.250 & 0.05 & 0.826 & insignificant \\
Residual & 5 & 23.17 & 4.6333 & & & 0.168 \\
Lack-of-fit & 3 & 20.50 & 6.833 & 5.13 & & \\
Pure error & 2 & 2.67 & 1.333 & & & \\
Total & 11 & 2781.60 & & & & \\
\hline
\end{tabular}

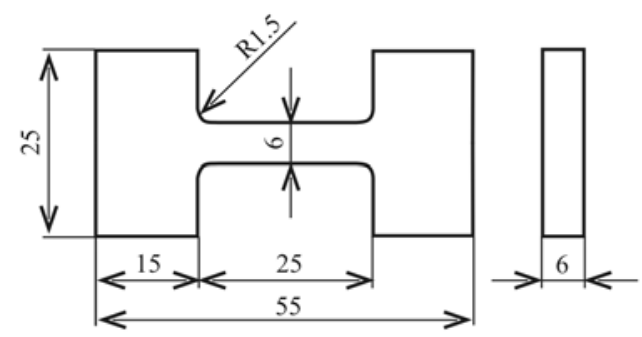

Fig. 5. Tensile specimen dimension, (unit: $\mathrm{mm}$ ).

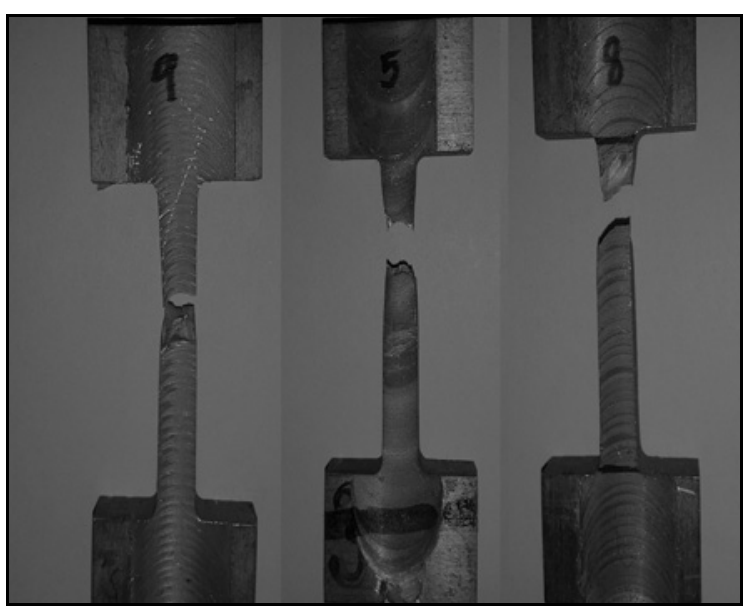

Fig. 6. Tested specimens.

are useful for the modelling \& analysis of problems and to optimize this response [15]. To determine the input-output relationships in the submerged friction welding process, a quadratic regression model can be considered [16, 17] as given in Eq. (1):

$$
\begin{gathered}
Y=a_{0}+b_{1} \omega_{1}+b_{2} v+b_{3} h+b_{11} \omega^{2}+b_{22} v^{2}+b_{33} h^{2}+ \\
+b_{1} b_{2} \omega v+b_{1} b_{3} \omega h+b_{2} b_{3} v h,
\end{gathered}
$$

where $Y$ is the tensile strength $(\mathrm{MPa}), \omega$ is the

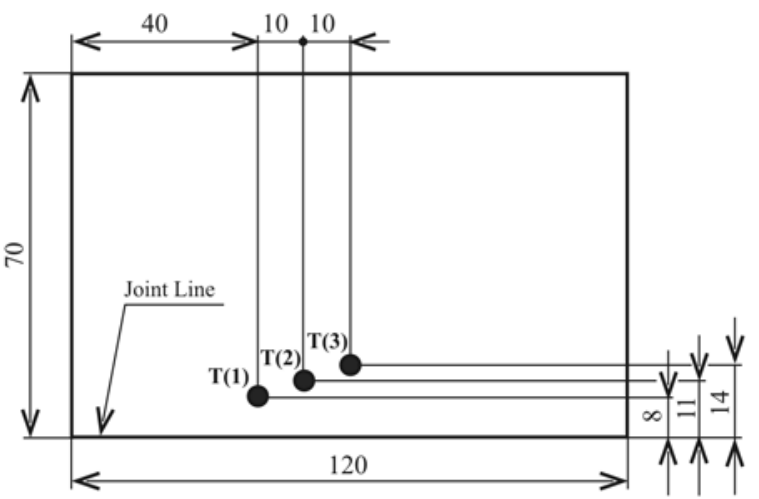

Fig. 7. Exact locations of thermal couples, (unit: $\mathrm{mm}$ ).

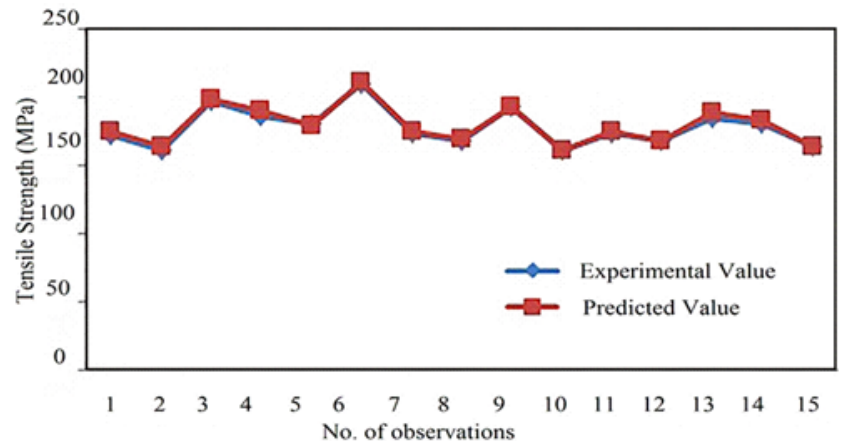

Fig. 8. Correlation between experimental and predicted tensile strength of welded joints.

rotational speed $(\mathrm{rpm}), v$ is the welding speed $\left(\mathrm{mm} \min ^{-1}\right)$, and $h$ is the water head $(\mathrm{mm})$.

The value of the coefficient was calculated using Minitab Software [19]:

$$
\begin{gathered}
Y=344.25-0.31 \omega-1.467 v-0.0583 h+0.00019 \omega^{2}+ \\
+0.013 v^{2}-0.0104 h^{2}-4.166 E-4 \omega v+ \\
+0.000125 \omega h+0.00167 v h .
\end{gathered}
$$



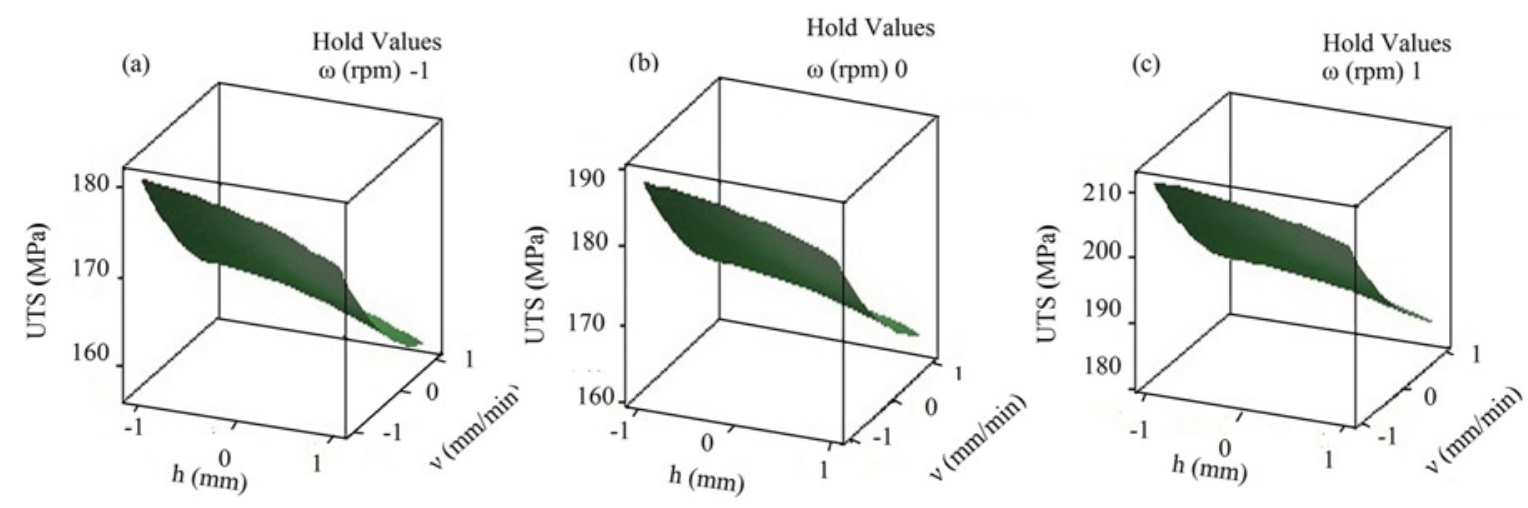

Fig. 9. Effect of water head, $h$, and welding speed, $v$, on UTS $(\mathrm{a}-\mathrm{c})$.
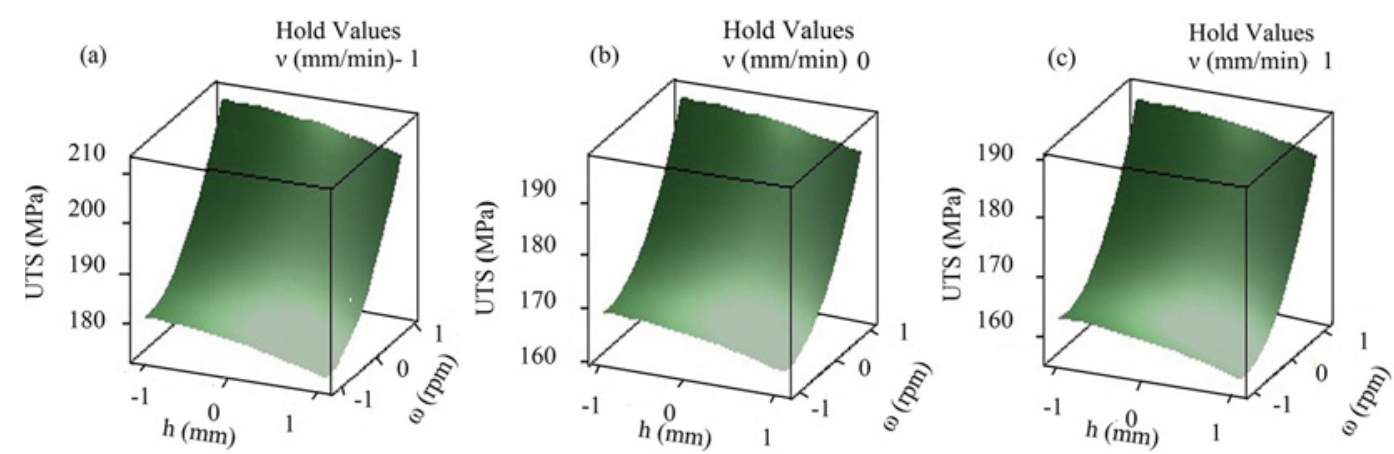

Fig. 10. Effect of water head, $h$, and rotational speed, $\omega$, on UTS (a-c).

\subsection{Checking the adequacy of model}

The Analysis of Variance (ANOVA) technique was used to check the adequacy of the developed model, as shown in Table 4. In this investigation, the desired level of confidence was considered to be $95 \%$. The significance of each of the model terms was checked, using $p$ values. The values of $p$ less than 0.05 indicate that the model terms are significant. The values of $p$ greater than 0.05 indicate that the model terms are not significant [18]. In this case, $A, B, A^{2}, B^{2}$ are significant model terms, and the "Lack of Fit" is not significant. The model presents a determination coefficient, $R^{2}$, of 0.9917 and an adjusted determination coefficient, adjusted $-R^{2}$, of 0.9767 , implying a high correlation between the experimental and the predicted results. Each predicted value matches its experimental value well, as shown in Fig. 8.

\subsection{Influence of parameters}

During each experimental run, among the three input process parameters studied in this work, any two input parameters were varied at a low level $(-1)$, medium level $(0)$ and high level $(+1)$. Figures $9 \mathrm{a}-\mathrm{c}$ indicate the response surface of the ultimate tensile strength $(\mathrm{MPa})$ by varying the water head, $h$, and welding speed, $v$, while the rotational speed, $\omega$, is held constant at low, medium, and high levels. Figure $9 \mathrm{c}$ indicates that the maximum ultimate tensile strength $(\mathrm{MPa})$ can be achieved, with decreases in a water head, $h$, and welding speed, $v$, while increasing rotational speed, $\omega$. Figures $10 \mathrm{a}-\mathrm{c}$ indicate the response surface of the ultimate tensile strength (MPa) by varying the water head, $h$, and rotational speed, $\omega$, while the welding speed, $v$, is held constant at low, medium, and high levels. Figure 10a indicates that the maximum ultimate tensile strength (MPa) can be achieved, with decreases in the water head, $h$, and welding speed, $v$, while increasing the rotational speed, $\omega$. Figures $11 \mathrm{a}-\mathrm{c}$ indicate response surface of the ultimate tensile strength (MPa) by varying the welding speed, $v$, and rotational speed, $\omega$, while the water head, $h$, is held constant at low, medium, and high levels. Figure 11a indicates that the maximum ultimate tensile strength $(\mathrm{MPa})$ can be achieved with a decrease in a water head, $h$, and welding speed, $v$ while increasing rotational speed, $\omega$.

\subsection{Desirability approach}

There are many statistical techniques available for solving multiple response problems. Among them, the desirability method is recommended due to its simplicity, flexibility, and availability of the software [19]. It is suggested that it gives accurate values of the ul- 

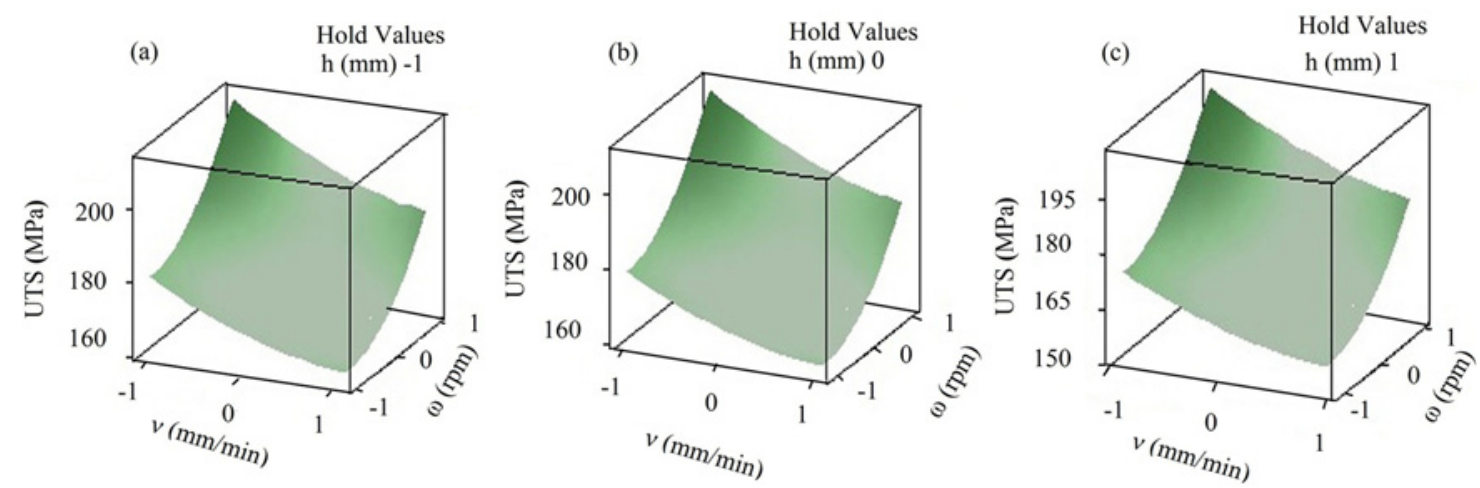

Fig. 11. Effect of welding speed, $v$, and rotational speed, $\omega$, on UTS $(\mathrm{a}-\mathrm{c})$.

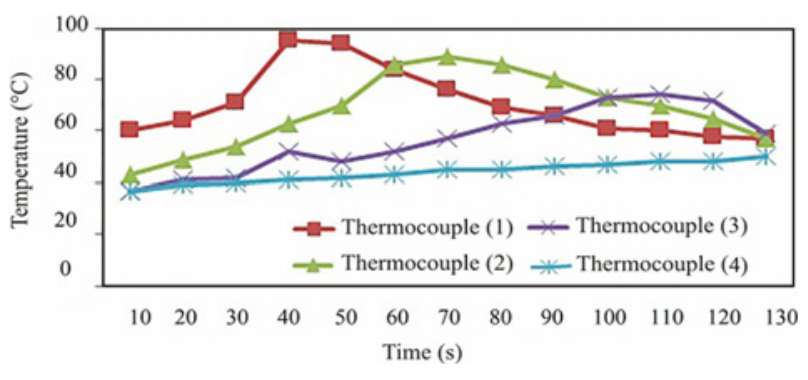

Fig. 12. Temperature histories of submerged SFSW.

timate strength of the submerged friction stir welded AA6061-T6 alloy. In this study, the maximum tensile strength of $211.46 \mathrm{MPa}$ during underwater welding of the 6061-T6 aluminium alloy was obtained at the rotational speed of $1200 \mathrm{rpm}$, welding speed of $60 \mathrm{~mm} \mathrm{~min}-1$ and water head of $10 \mathrm{~mm}$. During the normal FSW of AA6061-T6 alloy with optimized conditions, the maximum tensile strength was found $177 \mathrm{MPa}$.

\subsection{Temperature distribution}

Figure 12 shows the temperature distribution, where submerged FSW was performed on the AA6061-T6 alloy. The maximum weld temperature recorded is $95^{\circ} \mathrm{C}$ at $30^{\text {th }} \mathrm{s}$ in thermocouple 1 , and the maximum water temperature recorded is $50^{\circ} \mathrm{C}$ at $120^{\text {th }} \mathrm{s}$ in thermocouple 4 during the experiment. The temperature distribution of the normal FSW on AA6061-T6 alloy is shown in Fig. 13. The maximum weld temperature recorded is $228^{\circ} \mathrm{C}$ at the $40^{\text {th }} \mathrm{s}$ in thermocouple 1 , nearest to the weld region. The optimal underwater joint experiences lower peak temperature than the optimal normal joint. This means that the water cooling action effectively controls the temperature levels to increase the tensile strength of the weld sample by SFSW.

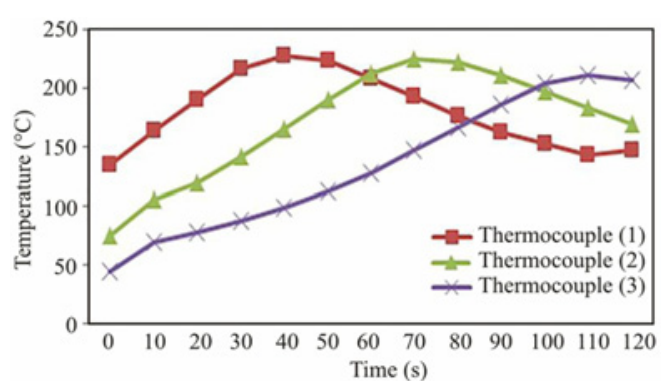

Fig. 13. Temperature histories of normal FSW.

\subsection{Microstructure}

Figures $14 \mathrm{a}-\mathrm{c}$ show the microstructure of the received material, FSW in air, and submerged in water. Coarse and inhomogeneous grain structures were observed in the received material. Significant grain refinement was achieved; moreover, the average grain size is 7 and $2.5 \mu \mathrm{m}$ for FSW in the air and submerged in water, respectively.

\section{Conclusions}

The following results were obtained by the experimental and analytical methods:

- The mathematical model for maximum ultimate tensile strength (UTS) was developed, and the prediction of this approach was in good agreement with the experimental results.

- From the RSM surface plot, it was observed that the value of the Ultimate Tensile Strength (UTS) increased by increasing the rotational speed, $\omega$ while decreasing both the welding speed, $v$, and water head, $h$.

- The SFSW process parameters were optimized to the maximum tensile strength of $211.46 \mathrm{MPa}$ of AA6061-T6 alloy using the desirability approach. The optimum condition of the rotational speed (rpm), the welding speed $\left(\mathrm{mm} \mathrm{min}^{-1}\right)$ and the water head $(\mathrm{mm})$ 

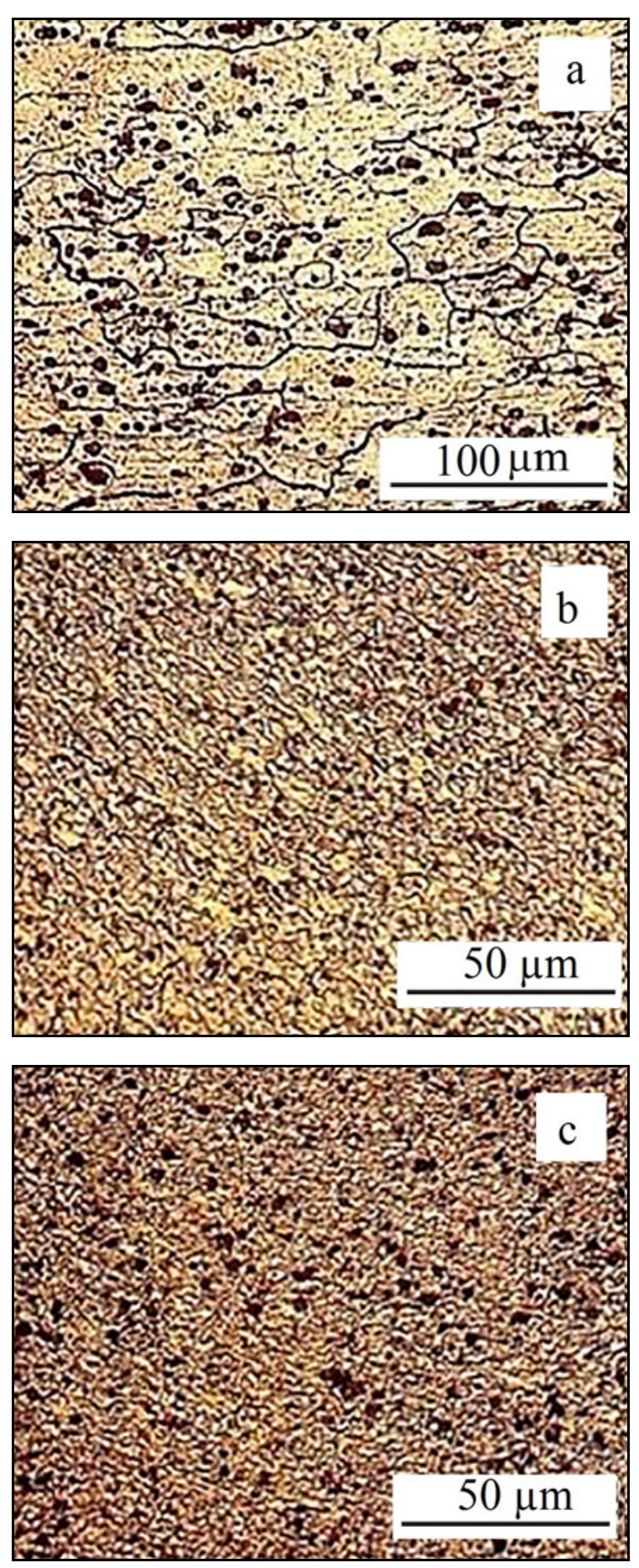

Fig. 14. Microstructures of received material (a), FSW in air (b), and FSW submerged in water (c).

was found to be $1200 \mathrm{rpm}, 30 \mathrm{~mm} \mathrm{~min}^{-1}$ and $10 \mathrm{~mm}$, respectively.

- The peak temperatures near the weld region (measured using thermocouple 1) were found to be 501 and $368 \mathrm{~K}$ for normal and underwater joints under optimized conditions.

- Grain size evolution in AA6061-T6 alloy during
FSW and SFSW was successfully examined, under optimization conditions. The grain size of 7 and $2.5 \mu \mathrm{m}$ was obtained for normal FSW and submerged FSW, respectively. Therefore, it can be concluded that the micro-grain structure is finer in SFSW than in FSW.

\section{Acknowledgements}

The authors gratefully acknowledge the Science \& Engineering Research Board, Department of Science and Technology (SERB-DST), New Delhi, India, for their financial assistance to conduct the research work through project no. SR/S3/MERC/0092/2011.

\section{References}

[1] Thomas, W. M., Nicholas, E. D., Needham, J. C., Murch, M. G., Templesmith, P., Dawes, C. J.: Friction Welding. US Patent-5460317. 1995.

[2] Mishra, R. S., Ma, Z. Y.: Mater. Sci. Eng. R, 50, 2005, p. 1. doi:10.1016/j.mser.2005.07.001

[3] Fratini, L., Buffa, G., Shivpuri, R.: Acta Materialia, 58, 2010, p. 2056. doi:10.1016/i.actamat.2009.11.048

[4] Hofmann, D. C., Vecchio, K. S.: Mater. Sci. Eng. A, 402, 2005, p. 234. doi:10.1016/j.msea.2005.04.032

[5] Zhang, H., Liu, H.: Materials and Design, 45, 2013, p. 208. doi:10.1016/j.matdes.2012.09.022

[6] Zhang, H. J., Liu, H. J., Yu, L.: Trans. Nonferrous Met. Soc. China, 23, 2013, p. 1114. doi:10.1016/S1003-6326(13)62573-X

[7] Liu, H. J., Zhang, H. J., Yu, L.: Materials and Design, 32, 2011, p. 1548. doi:10.1016/i.matdes.2010.09.032

[8] Liu, H. J., Zhang, H. J., Huang, Y. X., Yu, L.: Trans. Nonferrous Met. Soc. China, 20, 2010, p. 1387. doi:10.1016/S1003-6326(09)60309-5

[9] Zhang, H. J., Liu, H. J., Yu, L.: Materials and Design, 32, 2011, p. 4402. doi:10.1016/i.matdes.2011.03.073

[10] Liu, H. J., Zhang, H. J., Yu, L.: JMEPEG, 20, 2011, p. 1419. doi:10.1007/s11665-010-9787-x

[11] Fu, R. G., Sun, Z. Q., Sun, R. Ch., Li, Y., Liu, H. J., Liu, L.: Materials and Design, 32, 2011, p. 4825. doi:10.1016/i.matdes.2011.06.021

[12] Darras, B., Kishta, E.: Materials and Design, 47, 2013, p. 133. doi:10.1016/j.matdes.2012.12.026

[13] Rai, R., De, A., Bhadeshia, H. K. D. H., DebRoy, T.: Science and Technology of Welding and Joining, 16, 2011, p. 325. doi:10.1179/1362171811Y.0000000023

[14] Feng, X., Liu, H., Lippold, J. C.: Materials Characterization, 82, 2013, p. 97. doi:10.1016/j.matchar.2013.05.010

[15] Lakshminarayanan, A. K., Balasubramanian, V.: Trans. Nonferrous Met. Soc. China, 19, 2009, p. 9. doi:10.1016/S1003-6326(08)60221-6

[16] Udayakumar, T., Raja, K., Afsal Husain, T. M., Sathiya, P.: Materials and Design, 53, 2014, p. 226. doi:10.1016/j.matdes.2013.07.002

[17] Gopi, V., Manonmani, K.: Science and Technology of Welding and Joining, 17, 2012, p. 601. doi:10.1179/1362171812Y.0000000055 
[18] Paventhan, R., Lakshminarayanan, P. R., Balasubramanian, V.: Journal of Iron and Steel Research International, 19,2012 , p. 66. doi:10.1016/S1006-706X(12)60049-1
[19] Elatharasan, G., Senthil Kumar, V. S.: Procedia Engineering, 38, 2012, p. 3477. doi:10.1016/j.proeng.2012.06.401 